\title{
NOVEL TECHNIQUE FOR MAXIMIZING THE THERMAL EFFICIENCY OF A HYBRID PV/T SYSTEM USING PULSE WIDTH MODULATION
}

\author{
A. Bayoumi ${ }^{1}$, S. O. Abdellatif ${ }^{2}$, I.M. Mahmoud ${ }^{3}$, A. Sahbel ${ }^{4}$ \\ ${ }^{1,4}$ Teaching Assistant, Mechanical Engineering Department, The British University in Egypt, Cairo, Egypt \\ ${ }^{2}$ Assistant Lecturer, ${ }^{3}$ Teaching Assistant, E.E. Department, The British University in Egypt, Cairo, Egypt
}

\begin{abstract}
In this paper a comparison between numerical model and experimental work results for a fixed Photovoltaic/ Thermal (PV/T) hybrid system is presented. The simulation in this work is based on a numerical model in solving the equations and determining the Photovoltaic $(P V)$ cells thermal characteristics using both MATLAB and COMSOL Multiphysics. COMSOL is simulating the electromagnetic waves produced by the Sun through solving Maxwell's equations in three dimensions using Finite Elements Methods (FEM) and the sun irradiance is assumed to be Gaussian distribution across the twelve mourning hours. Beside that an experimental work is presented depending on the results conjured from the theoretical experience used in Comsol Multiphysics. A Pulse Width Modulator (PWM) is used to control the solenoid valve operation. In addition to the above a thermal analysis for the fixed PV modules and the piping water is presented where the output water temperatures, rate of heat transfer, overall heat transfer coefficient and thermal efficiency are calculated. As a result, a significant enhancement in the total thermal efficiency is observed with acceptable increase in the output water temperature.
\end{abstract}

Keywords: Cooling systems; DAQ; Hybrid; COMSOL MULTIPHYSICS; MATLAB; Solid work; Lab view.

\section{INTRODUCTION}

Solar energy is becoming one of the primary sources of energy replacing fossil fuels due to its abundance. Its versatility, abundance and environmental friendly have made it one of the most promising renewable sources of energy. The goal of achieving high photovoltaic conversion efficiency not only attributes as a scientific achievement and aids specialized application, but can also reduce the cost of large scale solar electrical generators.

Bakker et al. [1] analyzed a PV/T panel array where heat was extracted from the panels and stored underground in a heat exchanger. In winter, the heat could be extracted from the ground via a heat pump and used to heat potable water and support a floor heating system while increasing the electrical efficiency of the solar panel.

Chen et al. [2] developed a hybrid PV/T pump system using refrigerant fluid R134a as the heat carrying fluid. The coefficient of performance (COP) of the heat pump and electrical efficiency of the PV panel was measured at different condensing fluid flow rates and temperatures.

The largest PV/T solar panel installation in the United States was brought online in February 2012 in Rhode Island at Brown University's Katherine Moran Coleman Aquatics Center. In this application, 168-patented PV/T panels were installed on the center's roof, which under full sun exposure can provide enough electricity to light the building and heat the one million gallon swimming pool inside of it [3].

Yang et al. [4] developed a functionally graded material (FGM) is a PV layer, copper water pipes cast into plastic lumber that was bonded with thermal paste to the backside of a PV/T panel. Cooling water was pumped at various flow rates through the cast copper pipes to decrease the $\mathrm{PV} / \mathrm{T}$ panel temperature thus increasing $\mathrm{PV} / \mathrm{T}$ panel electrical efficiency by up to $2 \%$. This study also analyzed the thermal efficiency of the closed system design, and reported that a combined thermal and electrical efficiency of $71 \%$ could be achieved, compared to $53-68 \%$ total efficiency of other PV/T concepts. Herein, a simulation model for a hybrid PV/T open system is presented. A backside water pipe is heated by the influence of the photovoltaic modules results an enhancement in the total conversion efficiency of the solar system with increasing the output water temperature.

\section{HYBRID SYSTEM MODELLING}

A fixed PV module made of a polycrystalline Si Shown in figure (1) is simulated using an analytical solution of passion equation where carrier transport is assumed in one direction. This hybrid system is consists of four connected polycrystalline PV modules of total dimensions $1.0396 \mathrm{~m} 2$ area where the cell edge is taken to be $0.04 \mathrm{~m}$. The incident angle is set to be 30ofor winter season because the irradiance of the sun has a best angle on PV modules. 
The PV modules supported on a connected rod $0.9 \mathrm{~m}$ with base $0.98 \mathrm{~m} 2$ and AM $1.5 \mathrm{G}$ is assumed. The effect of cooling for the system by passing water in the backside Copper pipe of $0.012 \mathrm{~m}, 0.013 \mathrm{~m}$ for inner and outer diameters and $11.6 \mathrm{~m}$ length is embedded in the aluminum plate.

This model built in Solid work and transferred the design to the Comsol MULTIPHYSICS by the link live.

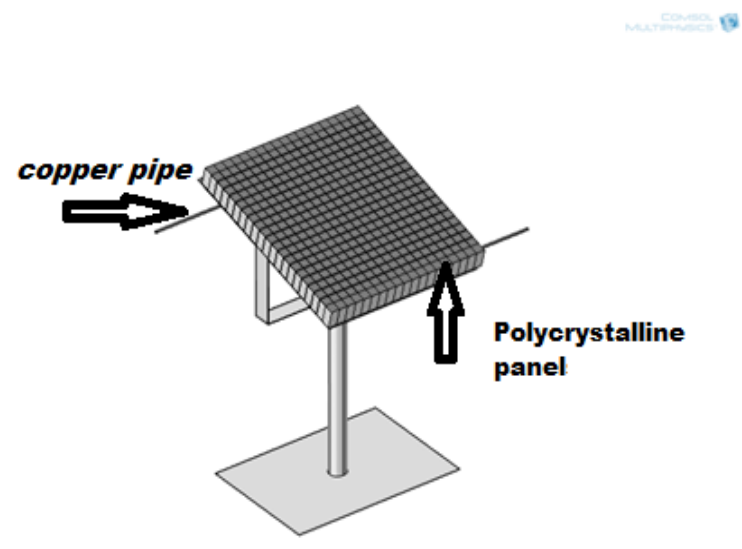

Fig (1) Polycrystalline PV/T hybrid system used in COMSOL.

In this study, forced convection does not only occur on the top surface of the PV panel, but also through the pipe mounted to the backside of the panel. Therefore, the total convective heat transfer is a combination of the heat transfer at the surface of the panel and the heat transfer from the flowing water in the pipe. The finite element analysis software being used in this study, COMSOL MULTIPHYSICS contains an open system laminar flow and conjugate heat transfer physics package, which is being used to model the convective heat transfer in the water pipe on the backside of the PV panel. This package is appropriate for this study, because of the inhomogeneous temperature field that is created as water flows from the inlet to the outlet of the pipe. COMSOL numerically solves the fully compressible continuity and momentum equations, which are the governing equations for the fluid flow, and are shown below in equations ( 1 and 2$)$, shown in [7].

$$
\begin{gathered}
\frac{d \rho}{d t}=\nabla \cdot(\rho u)=0 \\
\rho \frac{d u}{d t}+\rho u \cdot \nabla \mathrm{u}=\begin{array}{l}
-\nabla \mathrm{p}+\nabla \cdot\left(\mu\left(\nabla \mathrm{u}+(\nabla \mathrm{u})^{\mathrm{T}}\right)-\right. \\
23 \mu \nabla \cdot \mathrm{u} \text { I }(2)
\end{array}
\end{gathered}
$$

The heat equation is also solved, which is shown in equation (3).

$$
\rho C_{p} \mathrm{u} \cdot \nabla \mathrm{T}=\nabla \cdot(\mathrm{K} \nabla \mathrm{T})
$$

The long wave radiation heat loss can be calculated from equation (4).

$$
q_{l w}=\varepsilon \cdot \sigma \cdot\left(T_{P V}^{4}-T_{a m p}^{4}\right)
$$

A numerical model based on COMSOL Multiphysics simulation tool [8] for a hybrid PV/T is introduced as shown in figure (2). The silicon PV modules are heated by the electromagnetic waves produces by the sun through radiation heat transfer. This heated body (PV modules) transfers its heat to the aluminum plate and the copper pipe surface (outer and inner) by conduction. Finally the cooling liquid (water) is heated by convection.

The overall heat transfer coefficient is given by equation $(5,6$ and 7) and the rate of heat transfer calculated by equation (8) for an open thermodynamic system [9].

$$
\begin{gathered}
\frac{1}{\mathrm{UA}}=\frac{\mathrm{t}_{\mathrm{h}}}{\mathrm{K}_{\mathrm{Si}} \mathrm{A}}+\frac{\mathrm{t}_{\mathrm{h}}}{\mathrm{K}_{\mathrm{Al}} \mathrm{A}}+\frac{\ln \left(\frac{\mathrm{r}_{\text {in }}}{\mathrm{r}_{\text {out }}}\right)^{2}}{2 \pi \mathrm{K}_{\text {Pipe }} \mathrm{L}}+\frac{1}{\mathrm{~h}_{\mathrm{W}} \mathrm{a}}+\frac{1}{\mathrm{~h}_{\text {air }} \mathrm{a}} \\
\mathrm{A}=1 \times \mathrm{xW} \\
\mathrm{A}=2 \pi \mathrm{rL} \\
\mathrm{Q}=\mathrm{AU} \Delta \mathrm{T}
\end{gathered}
$$

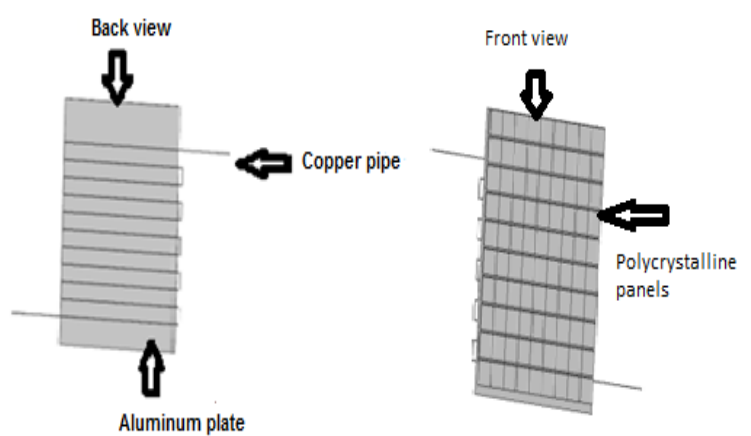

Fig (2) front and back view for a PV/T system used in COMSOL.

The thermal model modeled and analyzed in this study is identical to that modeled by Jones and Underwood [10], although the amount of energy applied to the PV cell that is converted to heat energy is calculated using the same method Kerzmann and Schaefer [11] utilize. The heat energy going into the PV cell is a function of the PV cell efficiency, $\eta_{P V}$, as shown below in equation (10) Using this calculated value for the PV cell efficiency, the amount of solar irradiance, $q_{\text {rad }}$ that is converted to heat energy, $Q_{\text {heat }}$ isthen calculated at each time step from equation (9). The steady state solution is finallyreached as the COMSOL solver converges.

$$
\mathrm{Q}_{\text {heat }}=\mathrm{q}_{\mathrm{rad}}\left(1-\eta_{\mathrm{pv}}\right)
$$


The PV cell electrical output efficiency can also be expressed as a function of PV cell power output, solar irradiance, and the PV cell surface area as shown in equation (10).

$$
\eta_{\mathrm{PV}}=\frac{\mathrm{v}_{\mathrm{mp}} \mathrm{I}_{\mathrm{mp}}}{\mathrm{q}_{\mathrm{rad}} \mathrm{A}}
$$

Post processing of the data recorded in the simulations is required to calculate the thermal efficiency, $\eta_{t h}$, of the PV/T panel [9]. First, the total amount of energy (solar irradiance) into the cell must be calculated, which is given by equation (11).

$$
\mathrm{E}_{\text {in }}=\mathrm{q}_{\mathrm{rad}} \mathrm{A}
$$

Next, the thermal energy of the extracted by the water per second must be calculated from equation (12).

$$
\mathrm{E}_{\text {water }}=\mathrm{m}_{\text {water }} \mathrm{C}_{\text {pwater }}\left(\mathrm{T}_{\text {out }}-\mathrm{T}_{\mathrm{in}}\right)
$$

The mass of the water passing through the reservoir per second can be calculated from the density and flow rate of the water, assuming unit depth of the reservoir. The thermal efficiency is simply given by equation (13).

$$
\eta_{\text {th }}=\frac{E_{\text {water }}}{E_{\text {in }}}
$$

\section{PV/T EXPERIMENTAL SETUP}

Figure (3) shows the experimental set-up was designed to investigate how the temperature affects the efficiency and power output of PV panel during operation and takes advantage of these heat losses.

A tracking PV/T system designed as two axial active tracking [13]. During the operation, a mechanical tracking system was used to modulate the power output from solar panel by regulate the Position of the photovoltaic module facing the sun. In other words this mechanical system makes the zenith angle [14] approaches to zero from sun rise to sun set to ensure that the maximum electrical power is extracted depends on solar irradiance as arrange from $400 \mathrm{~W} / \mathrm{m}^{2}$ to $980 \mathrm{~W} / \mathrm{m}^{2}$.A hybrid system combined between PV tracking and cooling systems was designed to cool the tracking module.

The experiment was conducted from 6:00 am to 6:00 pm. A Solar power meter was used to capture the daily global solar irradiation. Temperature measurements are important in these experiments and therefore calibrated K-type thermocouples were utilized. In the experiments, PV current, PV voltage temperature of panel and solar irradiation were collected. All the experimental test rig components that used have been calibrated. All readings are collected in June 2013.

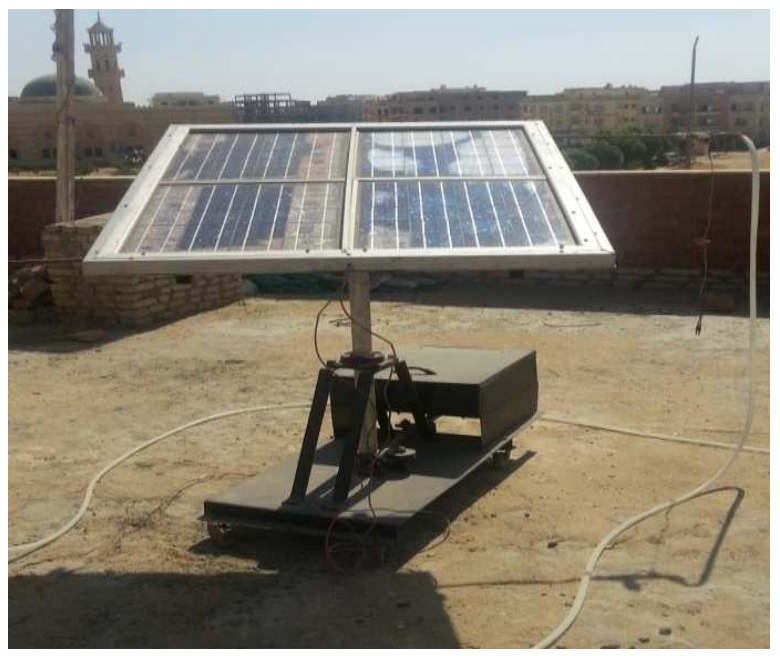

Fig (3): General view of the experimental system used.

In order to maximize the water temperature, a solenoid valve is used to control the water flow using a 5 volt thermistor. The temperature sensor signal is then acquired to the Lab view through a NI DAQ to be calibrated (see appendix A). Pulse width modulation (PWM) is token place to control the opening duration of the valve by varying the duty cycle of a square wave generated by Lab view. The frequency of the PWM is chosen to be $50 \mathrm{~Hz}$ as required by the solenoid valve. The block diagram and the front panel of the Lab view is shown in figures (4) and (5) respectively.

\section{THE RESULTS}

Figure (6) shows the variation of the rate of heat transfers $Q$ versus the input water temperature. A copper piping material is chosen due to the higher thermal conductivity and the rate of heat transfer increased by passes water cooling

Figure (7) shows the variation of time with the out temperature where the $\mathrm{x}$-axis indicate the time across the 12 hours of morning. The peak output temperature is observed at the point at which the Sun irradiance is maximum where the difference in temperature calculated at this point is $40{ }^{0} \mathrm{C}$. Figure represents the variation of time with the heat transfer rate per unit area where the same conclusion could be achieved at reference conditions $q_{\text {rad }}=1000 \mathrm{~W} / \mathrm{m}^{2}$. 


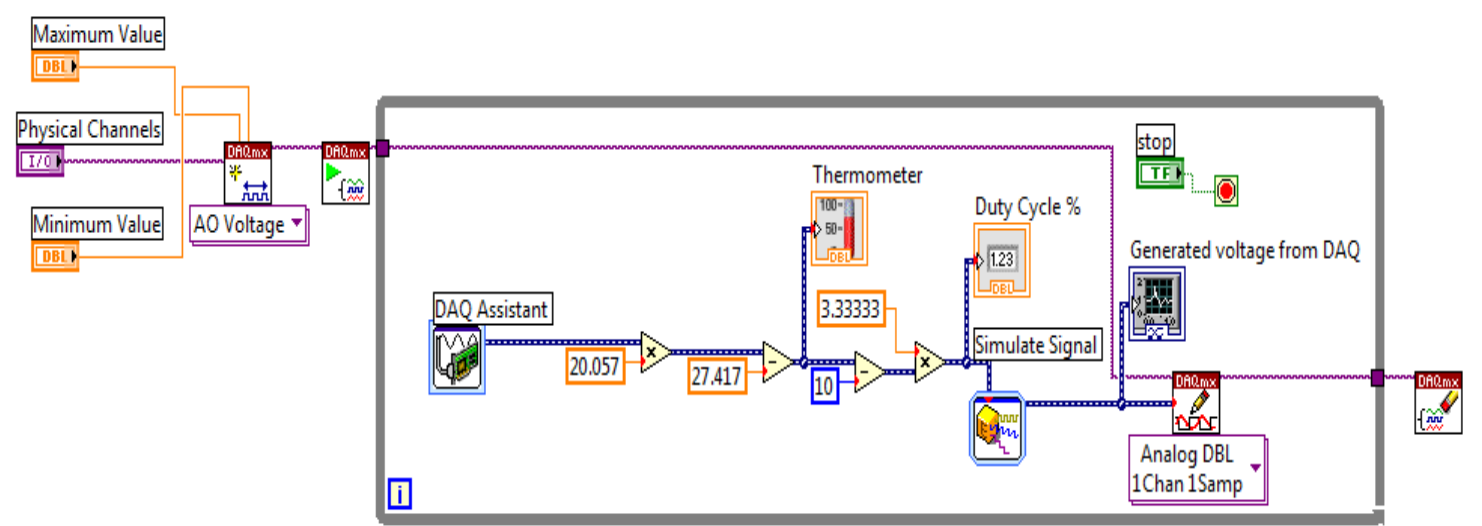

Fig (4) block diagram for PWM used in Lab view.

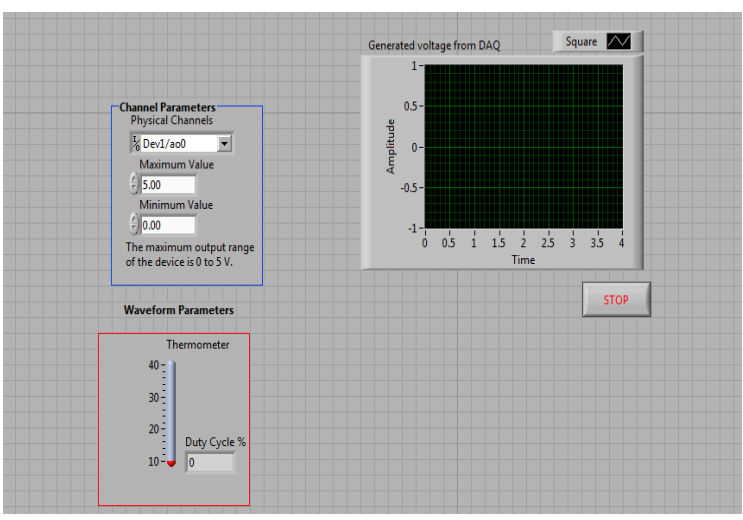

Fig (5) Labview controller for PWM

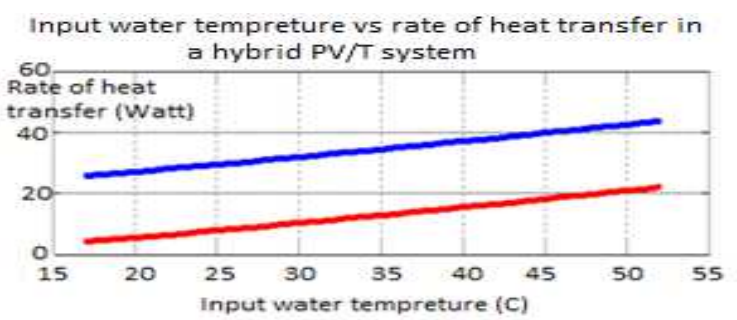

Fig (3) the rate of heat transfers vs. input water temperature.

\section{DISCUSSION}

Without cooling system the efficiency $\eta$ is $20 \%$, the fill factor $\mathrm{FF}=0.73$, the open circuit voltage $\mathrm{V}=21.6 \mathrm{~V}$, and the short circuit current $\mathrm{I}_{\mathrm{SC}}=2.9$ A. While in with cooling system $\eta$ is $30 \%$, the $\mathrm{FF}=0.85, \mathrm{~V}_{\mathrm{OC}}=21.6 \mathrm{~V}$, and $\mathrm{I}_{\mathrm{SC}}=3.8 \mathrm{~A}$.

The input temperatures of water in a copper pipe are ranged from 17 to $35{ }^{\circ} \mathrm{C}$, the output water temperatures achieved from 17 to $60{ }^{\circ} \mathrm{C}$ during the sunset in hours. That achieved the thermal efficiency $22 \%$ and the rate of heat transfer achieved $40 \%$.

Adding both electrical and thermal efficiency, the total conversion efficiency reaches $52 \%$. To conclude all the above, the suggested hybrid system results an increase of $32 \%$ over that of single PV system as an $10 \%$ increase in PV electrical efficiency is detected and a new $22 \%$ thermal efficiency is obtained by making use of the wasted heat from the backside of the PV panels.

\section{CONCLUSIONS}

The present work introduces a PV/Thermal hybrid system where the efficiency of the PV modules is calculated with and without the cooling water system. A $10 \%$ increase in efficiency is recorded due to passing the water in the backside pipes. This increase reflects on the maximum power which reach 60 watt. On the other hand the water output temperature is almost 30 OC higher than the input temperatures which make this system able to work as water heating system. Finally the total system efficiency was calculated by adding both the thermal and the PV efficiency and it was found to be more than $50 \%$. The hardware Implementation and the experimental testing are considered as a future work.

\section{REFERENCES}

[1] M. Bakker, H. A. Zondag, M. J. Elswijk, K. J. Strootman, M. J. M. Jong, "Performance and costs of a roof-sized PV/thermal array combined with a ground coupled heat pump", Solar Energy 78 (2005), pp. 331339.

[2] H. Chen, Saffa B. Riffat, Yu Fu, "Experimental study on a hybrid photovoltaic/heat pump system, Applied Thermal Engineering” 31 (2011), pp. 4132-4138. 
[3] Rowan Sharp, "Brown's Hybrid Solar Panels a First for RI." Eco RI News: Rhode Island's Environmental News Source 26 February (2012). Providence, RI.<www.ecoRI.org>.

[4] D. J. Yang, Z. F. Yuan, P. H. Lee, and H. M. Yin, "Simulation and experimental validation of heat transfer in a novel hybrid solar panel", International Journal of Heat and Mass Transfer 55 (2012), pp. 10761082.

[5] O. Lipscombe, "MultiphysicsModeling of Sensors and Actuators", Dover Publications, New York, NY, (2013), pp. 34-81.

[6] Reference solar spectral irradiance: Air mass 1.5, National Renewable Energy Lab. http://rredc.nrel.gov/solar/spectra/am1.5/. Accessed 16 July (2008).

[7] R. Byron Bird, Warren E. Stewart, and Edwin N. Lightfoot, Transport Phenomena: Second Edition, New York: John Wiley and Sons, Inc., (2007), pp 122-136.

[8] Comsol, Version 4.2, http://www.comsol.com.

[9] The Department of Energy DOE, "FUNDAMENTALS HANDBOOK - THERMODYNAMICS, HEAT TRANSFER, AND FLUID FLOW" - Volume 2 of 3", Washington, United State of America, June (1992), pp. 11-25.

[10] A.D. Jones and C.P. Underwood, "A Thermal Model for Photovoltaic Systems", Solar Energy 70 (2001), pp. 349-359.

[11] Tony Kerzmann and Laura Schaefer, "System simulation of a linear concentrating photovoltaic system with an active cooling system", Renewable Energy 41 (2012), pp. 254-261.

\section{BIOGRAPHIES}

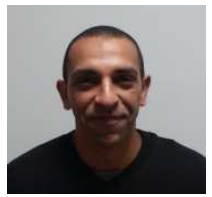

A. Bayoumi: received the B.Sc. degree in Mechatronics engineering mechanical department from The Higher Technological Institute, Tenth of Ramadan City, Egypt, in 2007 and the M.Sc. student in Mechatronics at Ain Shams University, Cairo, Egypt, Currently. Currently $\mathrm{He}$ is enrolled as an demonstrator in the Mechanical engineering department in the British University in Egypt (BUE) His research interests lie in the field of renewable energy especially PV.

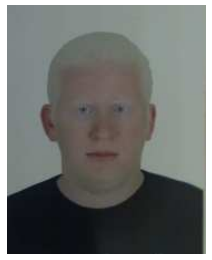

Sameh O. Abdellatif: received the B.Sc. degree in Electronics and communication from Ain Shams University, Cairo, Egypt, in 2009 and the M.Sc. degree in Semiconductor nano-structures from Ain Shams University, Cairo, Egypt, in 2012. Currently $\mathrm{He}$ is enrolled as an assistant lecturer in the Electrical engineering department in the British University in Egypt (BUE) and a research assistant in the Egypt Nanotechnology Center (EGNC). His research interests lie in the field of modeling and simulation of inorganic semiconductor nano-structures where he published some scientific papers in the last two years.

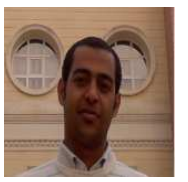

Ibrahem M. Mahmoud: received the B.Sc. degree in Electrical Power and Machines from Helwan University, Cairo, Egypt, in 2008 and a M.Sc. Student in Renewable Energy at British University in Egypt, Cairo, Egypt, Currently. Currently $\mathrm{He}$ is enrolled as a demonstrator in the Electrical engineering department in the British University in Egypt (BUE). His research interests lie in the field of renewable energy especially PV and Wind energy systems. He is also involved in more than one funded project in the renewable energy field.

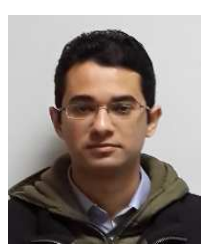

Anwar M. Sahbel: received the B.Sc. degree in Mechatronics engineering mechanical department from The Higher Technological Institute, Tenth of Ramadan City, Egypt, in 2009 and the M.Sc. student in Mechatronics at Ain Shams University, Cairo, Egypt, Currently. Currently $\mathrm{He}$ is enrolled as an demonstrator in the Mechanical engineering department in the British University in Egypt (BUE) His research interests lie in the field of renewable energy especially PV. 